\title{
Crescimento de Osso, Músculo e Gordura dos Cortes da Carcaça de Cordeiros e Cordeiras em Diferentes Métodos de Alimentação ${ }^{1}$
}

\author{
Gilberto Teixeira da Rosa², Cleber Cassol Pires ${ }^{3}$, José Henrique Souza da Silva ${ }^{4}$, Liziany Müller ${ }^{5}$
}

RESUMO - O experimento foi realizado no Setor de Ovinocultura do Departamento de Zootecnia da Universidade Federal de Santa Maria, com o objetivo de estudar o crescimento relativo de osso, músculo e gordura do pescoço, paleta, costela e perna da carcaça de cordeiros e cordeiras, sendo utilizados 22 machos inteiros e 23 fêmeas da raça Texel. Desses, sete foram abatidos no início do experimento e os demais aos pesos de 25 ou $33 \mathrm{~kg}$. Ovelhas mais cordeiros foram distribuídos em três métodos de alimentação: M1 Silagem de milho e concentrado, apenas aos cordeiros até o desmame, aos 60 dias; M2 - Silagem de milho e concentrado, apenas aos cordeiros até o desmame, aos 45 dias e M3 - Silagem de milho e concentrado para ovelha mais cordeiro até o desmame com 60 dias. Após o desmame, os cordeiros receberam silagem mais concentrado. Foi utilizado um delineamento inteiramente casualizado em arranjo fatorial $3 \times 2 \times 2$ ( 3 métodos, 2 sexos e 2 pesos de abate). A determinação do crescimento foi obtida através da equação $\log y=\log a+b \log x$, utilizandose o logaritmo do peso de osso, músculo e gordura em função do logaritmo do peso da carcaça fria. Para pescoço, os coeficientes alométricos de osso para machos variaram de 0,23 a 0,31 e, para fêmeas, de 0,67 a 0,73 , enquanto que o crescimento muscular, exceto para um dos métodos de alimentação, foi isométrico em relação à carcaça; já os coeficientes para gordura foram superiores à unidade, independentemente de sexo e método de alimentação. Quanto ao osso da paleta, os coeficientes alométricos variaram de 0,64 a 0,82 e o crescimento muscular, nos três métodos de alimentação, foi precoce apenas para machos, enquanto que para fêmeas foi isométrico. A gordura, independentemente de métodos de alimentação e sexo, apresentou crescimento tardio com coeficientes entre 1,42 e 1,68. Na perna, independentemente de métodos de alimentação e sexo, o osso apresentou crescimento precoce com coeficientes alométricos variando de 0,56 a 0,77 , no entanto, para músculo, os coeficientes não diferiram da unidade, enquanto para gordura os coeficientes variaram de 1,67 a 1,96 .

Palavras-chave: coeficientes alométricos, gordura, músculo, osso, ovinos

\section{Fat, Muscle and Bone Growth of Carcass Cuts of Male and Female Lambs in Different Feeding Methods}

\begin{abstract}
The experiment was done at the Universidade Federal de Santa Maria Animal Science Department Ovinoculture Sector, it had the was carried out to study the relative bone growth, muscle and adiposity of the neck, shoulder-blade, rib and leg of carcass of the lambs. It was used 45 lambs (Texel), 22 non-castrated male and 23 females. From that group, seven were slaughtered in the beginning of the experiment and the other ones when they reached 25 or $33 \mathrm{~kg}$. Sheep and lambs were allotted to three feeding methods, M1- Corn silage and concentrated only to the lambs, up to the weaning, at 60 days, M2- Corn silage and concentrated only to the lambs up to the weaning, at 45 days and M3- corn silage and concentrated to sheeps and lambs up to the weaning with 60 days. The lambs were randomly distributed into collective boxes and submitted to three feeding methods. It was used a randomly delineation with a factorial arrangement of 3:2:2 ( 3 methods, 2 sexes and 2 weights of slaughter). The growth determination was obtained through the equation $\log y=\log a+b \log x$, using the logarithm of the bone muscle and fat weight based on the logarithm of the cold carcass weight. The allometric coefficients to the neck bone, to males, varied of 0.23 to 0.31 and to females, the variation was from 0.67 to 0.73 , whereas the muscle growth, excepting the feeding methods, was isometric concerning carcass, and the fat coefficients was superior in relation to unity, regardless feeding methods and sex. Concerning the shoulder-blade bone the allometric coefficients varied to 0.64 from 0.82 and the muscle growth, in the three feeding methods, was anticipated only to males, whereas to females was isometric and fat, regardless sex and feeding methods and presented late growth, with coefficients varying from 1.42 to 1.68 . In the leg bone, regardless sex and feeding methods, the bone presented premature growth with allometric coefficients varying to 0.56 from 0.77 , but to muscle the coefficients do not differ from unity, whereas to fat the coefficients ranged from 1.67 to 1.96 .
\end{abstract}

Key Words: allometric coefficients, fat, muscle, bone, ovine

\footnotetext{
1 Parte da dissertação de Mestrado apresentada à UFSM.

2 Zootecnista, Mestre na UFSM. E.mail: a9860181@zipmail.com.br

3 Médico Veterinário, Prof Dr. do Depto de Zootecnia da UFSM, Campus Universitário, Camobi km 09,CCR/Departamento de Zootecnia,

cep: 97.119-900, Santa Maria - RS. E.mail: cpires@ccr.ufsm.br

${ }^{4}$ Engenheiro-Agrônomo, Prof. Dr. do Depto de Zootecnia da UFSM. E.mail: jhen@ccr.ufsm.br

5 Aluna do curso de Zootecnia da UFSM, Bolsista FAPERGS. E.mail: lizianymuller@bol.com.br
} 


\section{Introdução}

Em condições nutricionais ótimas, o crescimento de cada tecido segue uma taxa própria até alcançar determinado tamanho pela constituição genética do animal.

Segundo Hafez \& Dyer (1972), ratos machos e fêmeas crescem iguais até o início da puberdade. A partir deste ponto, os machos crescem com maior rapidez, sendo maiores que as fêmeas ao atingirem a maturidade. O mesmo autor ainda cita que os ossos dos machos inteiros são mais grossos que os das fêmeas, principalmente nas regiões do corpo de desenvolvimento precoce (cabeça, peito e extremidades) e que a castração elimina a secreção dos andrógenos, produzidos pelos testículos, reduzindo a espessura dos ossos dos machos à mesma magnitude do que o das fêmeas.

Wynn \& Twhaites (1981), trabalhando com cordeiros da raça Merina e Cruza (Border Leicester x Merina), observaram que os animais cruzas possuem maior quantidade de osso que os animais puros, quando comparados com pesos de abate de 10, 40 e $50 \mathrm{~kg}$ de peso vivo. Huidobro \& Villapadierna (1992) observaram que a proporção de osso na meia carcaça de cordeiros, abatidos com 15; 25 e $30 \mathrm{~kg}$ de peso vivo, foi maior para animais abatidos aos $25 \mathrm{~kg}$, com um coeficiente de crescimento de 0,9557 . Silva et al. (1998) também verificaram que a proporção de osso na carcaça de cordeiros (machos) desmamados aos 50 dias de idade e abatidos com 20,92; 28,30; e 32,57 $\mathrm{kg}$ de peso vivo foi maior no peso de abate intermediário, ou seja, $28,30 \mathrm{~kg}$, com coeficiente de alometria de 0,6733 , respectivamente.

O crescimento do tecido muscular é caracterizado até o momento antes do nascimento, pelo aumento do número de células e, após o nascimento, pelo aumento do tamanho das células.

De acordo com Berg \& Butterfield (1976), as causas do crescimento diferencial que ocorrem entre os diversos músculos são: 1) na fase pré-natal, os músculos estão estimulados pela tenção passiva, motivados pelo crescimento do esqueleto; 2 ) na fase pós-natal imediata ocorre grande mudança no peso relativo da musculatura, que está em parte influenciado pelas funções do músculo; 3 ) na fase pré-puberal e adolescência, os músculos crescem a uma velocidade uniforme e há grande aumento em tamanho, mas com pouca mudança no peso relativo; 4) na fase de terminação ocorre aumento da proporção relativa da musculatura do macho inteiro em relação ao castrado e é caracterizada pela constância na liberação de hormônios androgênicos, sendo que os machos castrados apresentam pequena alteração na musculatura, provavelmente devido à deficiência na produção e liberação desses hormônios. Butterfield \& Thompson (1983) afirmam que a distribuição do peso dos músculos entre animais, de formato grande e pequeno, indica uma menor proporção de músculos tardios em relação à musculatura total nos animais de formato grande.

A gordura é o tecido de maior variabilidade no animal, seja do ponto vista quantitativo, seja por sua distribuição e função biológica fundamental de armazenamento de energia para os períodos de escassez alimentar.

O tecido adiposo tem papel fundamental nas diferenças de composição corporal entre touros, machos castrados e fêmeas, sendo que essas iniciam a deposição de gordura com pesos menores do que os machos castrados e touros, e os machos castrados em pesos menores que os machos inteiros (Hafez, 1972). Berg et al. (1978) verificaram que a gordura apresenta velocidade de crescimento reduzida nas extremidades distais e próximas dos membros anteriores sendo que, longitudinalmente à linha dorsal, o coeficiente de crescimento é baixo no pescoço e regiões da garupa, aumentando na região do dorso; contudo, apresenta alto coeficiente ventralmente na região do flanco, peito e costelas.

Jones (1982) encontrou coeficiente de alometria de 1,$23 ; 0,74$ e 1,05 para gordura subcutânea, intramuscular e pélvico - renal. Huidobro \& Cañeque, (1994) afirmam que o estudo do desenvolvimento da gordura é muito importante, já que as proporções de cada depósito de gordura afeta o valor comercial das carcaças. Prova disso é que os principais sistemas de classificação de carcaças utilizam medições sobre o tecido adiposo, e os programas de seleção genética, utilizados para diminuir o excesso de gordura nas carcaças, estão baseados em medições da gordura subcutânea. O trabalho teve o objetivo de avaliar o crescimento de osso, músculo e gordura dos cortes da carcaça de cordeiros e cordeiras.

\section{Material e Métodos}

O trabalho foi realizado no Setor de Ovinocultura do Departamento de Zootecnia da Universidade Federal de Santa Maria, RS, sendo utilizados 45 cordei-

R. Bras. Zootec., v.31, n.6, p.2283-2289, 2002 
ros, machos não castrados (22) e fêmeas (23) da raça Texel. Desses, sete foram abatidos no início do experimento 24 horas após o nascimento e os demais assim que atingiam os pesos de 25 ou $33 \mathrm{~kg}$.

Os cordeiros remanescentes foram distribuídos, aleatoriamente, 24 horas após o nascimento, com suas respectivas mães, em três métodos de alimentação: M1- Alimentação com silagem de milho para cordeiro+ovelha, com fornecimento de concentrado apenas aos cordeiros na forma de creep feeding do nascimento ao desmame, aos 60 dias de idade, M2Alimentação com silagem de milho para cordeiro+ovelha, com fornecimento de concentrado apenas aos cordeiros na forma de creep feeding, do nascimento ao desmame aos 45 dias de idade e M3Alimentação com silagem de milho+concentrado com uma proporção de 70:30 na matéria seca (MS) para o conjunto ovelha mais cordeiro do nascimento ao desmame aos 60 dias de idade.

Todos os cordeiros eram oriundos de parto simples, sendo o M1 e M3 constituídos de 13 cordeiros ( 7 machos e 6 fêmeas) e o M2 de 12 cordeiros (6 machos e 6 fêmeas).

Os animais foram abatidos aos $25 \mathrm{~kg}$ ou aos $33 \mathrm{~kg}$ de peso vivo, na proporção de $50 \%$ machos e $50 \%$ fêmeas para cada peso de abate. Os mesmos, em cada método de alimentação, foram alimentados num galpão coberto com telha de amianto em baias coletivas com piso revestido de cimento.

Após o desmame, cada lote de cordeiro permaneceu em suas baias recebendo uma dieta contendo $16,7 \%$ de PB e $69,4 \%$ de NDT, formulada a partir de silagem de milho e um concentrado composto de milho desintegrado, farelo de soja, fosfato bicálcico, calcário calcítico e sal comum numa proporção de volumoso:concentrado de 50:50 na matéria seca.

Foi adotado um delineamento inteiramente casualizado em arranjo fatorial 3 × 2 × 2 (3 métodos, 2 sexos e 2 pesos de abate).

$\mathrm{O}$ abate final foi realizado à medida que cada cordeiro atingia o peso estabelecido no início do experimento, ou seja, 25 ou $33 \mathrm{~kg}$. Após o abate, a carcaça foi resfriada por 24 horas a uma temperatura de $2^{\circ} \mathrm{C}$ e, logo após, dividida através de um corte longitudinal iniciado na sínfese ísquio-pubiana e finalizado na última vértebra cervical, obtendo-se, assim, metades aproximadamente simétricas.

$\mathrm{Na}$ meia carcaça esquerda, foi realizada a separação do pescoço, paleta, costela e perna, os quais foram pesados separadamente. O corte do pescoço foi feito entre a $3^{\mathrm{a}} \mathrm{e} 4^{\mathrm{a}}$ vértebra cervical. A costela foi seccionada entre a última vértebra cervical e a primeira torácica e a última lombar e a primeira sacral; o corte da paleta foi obtido liberando-se a escápula da costela e, na porção média dos ossos do carpo e a perna, foi seccionada na articulação da última vértebra lombar e primeira sacral e na porção média dos ossos do tarso. Paleta, costela, perna e pescoço foram dissecados para se obter as quantidades de osso, músculo e gordura.

A determinação do crescimento foi realizado através da equação exponencial $\mathrm{y}=\mathrm{ax}{ }^{\mathrm{b}}$, de Huxley (1932) transformada logaritmicamente em $\operatorname{logy}=$ $\log a+b \log x$, onde se utilizou o logaritmo do peso de osso, músculo e gordura do pescoço, paleta, costela e perna, respectivamente, em função do logaritmo do peso de carcaça fria (PCF). As análises estatísticas foram realizadas no Núcleo de Processamento de Dados da UFSM, através do programa estatístico SAS (SAS 1996). Para verificação da hipótese $b=1$, foi utilizado o teste " $\mathrm{t}$ " (Student), com nível de significância de $(\mathrm{P}<0,05)$.

\section{Resultados e Discussão}

Os coeficientes de alometria encontrados para osso, músculo e gordura do pescoço na (Tabela 1) indicam que o osso é de desenvolvimento precoce $(b<1)$, independentemente de sexo e método de alimentação, sendo os menores valores referentes aos cordeiros machos, indicando que, nessa categoria, os ossos do pescoço crescem mais rápido, o que pode explicar a maior espessura de pescoço dos machos em relação às fêmeas.

$\mathrm{O}$ crescimento muscular do pescoço foi afetado pelo método de alimentação, pois é isogônico nos métodos 1 e 2 e precoce no método 3. Isso se explica devido aos animais do M3 terem sido desmamados mais pesados em consequiência da boa produção de leite das mães, uma vez que as mesmas recebiam uma dieta constituída de silagem e concentrado, enquanto que as dos outros tratamentos recebiam apenas silagem de milho. Quanto à gordura, o crescimento foi tardio, independentemente de sexo e método de alimentação, o que está de acordo com Santos et al.(1999), quando verificaram que o "estado de engorduramento" aumenta nas diferentes partes da carcaça de cordeiros com o avanço da idade e aumento do peso.

Huidobro \& Villapadierna (1992) encontraram

R. Bras. Zootec., v.31, n.6, p.2283-2289, 2002 
Tabela 1 - Parâmetros estimados das equações de alometria e erro padrão para osso, músculo e gordura do pescoço em relação ao peso de carcaça fria (PCF) de cordeiros machos $(M)$ e fêmeas $(F)$ em diferentes métodos de alimentação (M1, M2 e M3), e teste $\mathrm{t}(\mathrm{Ho}: \mathrm{b}=1)$

Table 1 - Estimated parameters of alometric equations and pattern error for bone, muscle and neck fat related to the cold carcass weight (PCF) of males lambs (M) and female lambs ( $F$ ) in different feeding methods (M1, M2 and M3), and t test (ho:b=1)

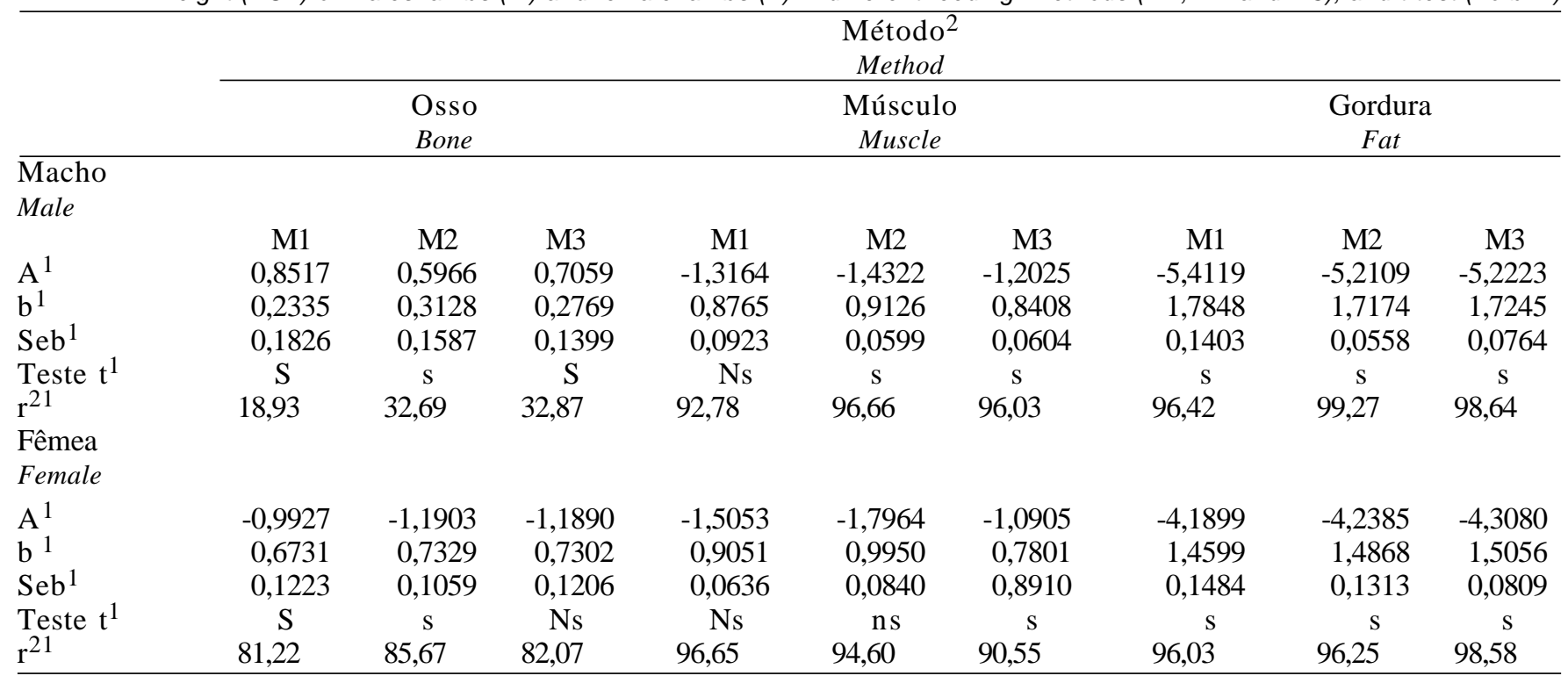

1. $A=$ interceptor; $b=$ coeficiente de alométria; $S e b=$ erro-padrão; Teste $t: s=$ significativo para $(P<0,05)$, ns = não-significativo para $(P>0,05) ; r^{2}=$ Coeficiente de determinação.

2. $M 1$ = método um; $M 2$ = método dois; $M 3$ = método três.

1. $A=$ intercept; $b=$ alometric coefficient; $\operatorname{Se} b=$ standard error; $t$ test: $s=$ significant at $P<.05, n s=$ not significant at $(P>.05) ; r^{2}=$ coefficient of determination. 2. $M 1=$ method one; $M 2=$ method two; $M 3=$ method three.

coeficientes de alometria de 0,848 para osso, 0,942 para músculo e 0,726 para gordura do pescoço, em relação ao peso da meia carcaça de animais abatidos aos 25 ou $35 \mathrm{~kg}$.

Observa-se na Tabela 2 que, independentemente de sexo e métodos de alimentação, o crescimento ósseo da paleta foi precoce e o do músculo foi precoce apenas para machos $(b<1)$, enquanto que para as fêmeas, nos três métodos de alimentação, o crescimento muscular acompanhou o crescimento da carcaça. Esses resultados estão de acordo com Butterfield (1968) et al., quando afirmam que o sexo influencia o crescimento dos tecidos do corpo e a composição da carcaça e que o crescimento dos músculos da parte dianteira de machos inteiros são de crescimento precoce em relação ao das fêmeas.

Os coeficiente alométricos para gordura foram, para sexo e método de alimentação, significativamente maiores que a unidade, caracterizando um crescimento tardio. Roque et al. (1999) encontraram coeficientes de crescimento para osso da paleta em relação à carcaça para as raças Merino, Corriedale, Ideal, Romney Marsh e Texel, com valores de 1,115;
1,$004 ; 0,525 ; 0,546$ e 0,776 e, para o músculo, os coeficientes foram 1,$312 ; 1,436 ; 1,462 ; 1,198$ e 0,765 , respectivamente, caracterizando um crescimento tardio, com exceção da raça Texel, que foi o genótipo usado neste experimento. Com relação à gordura, os resultados do presente estudo são inferiores aos encontrados para a raça Merina, com coeficiente de 5,173 e próximos aos encontrados pelo mesmo autor para as raças Ideal, Corriedale, e Texel, que foram 1,$943 ; 1,598$ e 2,127 , respectivamente.

Na Tabela 3, observa-se que o osso da costela apresentou coeficientes de crescimento isométricos para machos $(b=1)$, e para fêmeas maior que a unidade $(b>1)$. Observa-se, também, que o e o crescimento relativo do músculo e da gordura, do mesmo corte, foi tardio.

Huidobro \& Villapadierna (1992) verificaram, em cordeiros da raça Manchega, coeficientes de crescimento do osso, músculo e gordura da costela de 0,533 ; 0,922 e 0,709 , respectivamente, em relação ao peso da meia carcaça. Santos (1999), em machos inteiros da raça Santa Inês, verificaram coeficientes de crescimento de 0,498 para osso, 0,982 para músculo e 
Tabela 2 - Parâmetros estimados das equações de alometria e erro padrão para osso, músculo e gordura da paleta em relação ao peso de carcaça fria (PCF) de cordeiros machos $(M)$ e fêmeas $(F)$ em três métodos de alimentação (M1, M2 e M3) e teste t $(\mathrm{Ho}: \mathrm{b}=1)$

Table 2 - Estimated parameters of alometric equations and pattern error for bone, muscle and shoulder fat related to the cold carcass weight (PCF) of male lambs (M) and female lambs (F) in three feeding methods (M1, M2 and M3), and t test (ho:b=1)

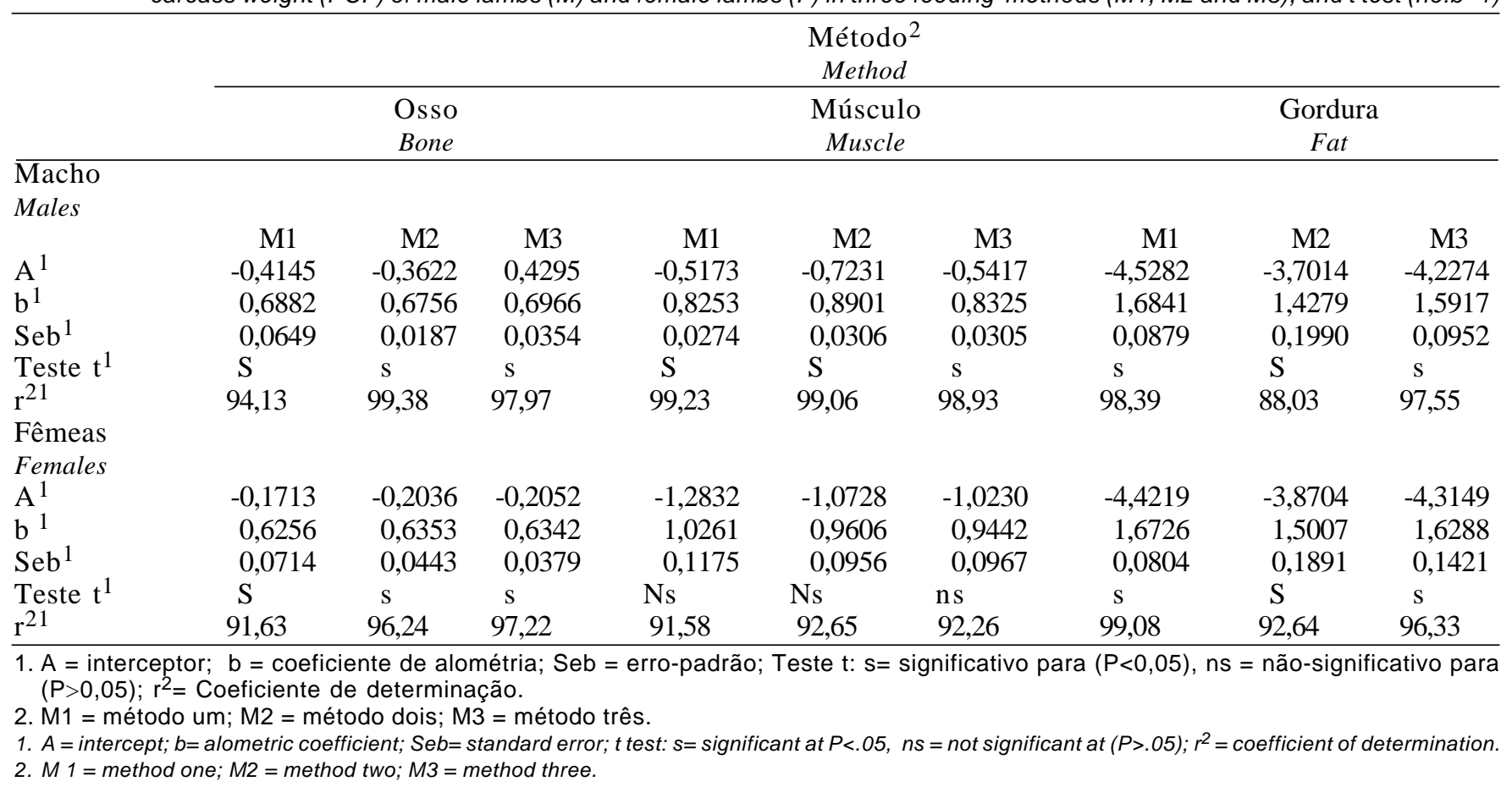

Tabela 3 - Parâmetros estimados das equações de alometria e erro padrão para osso, músculo e gordura da costela em relação ao peso de carcaça fria (PCF) de cordeiros machos (M) e fêmeas (F) em diferentes métodos de alimentação (M1, M2 e M3) e teste t $(\mathrm{Ho}: \mathrm{b}=1)$

Table 3 - Estimated parameters of alometric equations and pattern error for bone, muscle and ribs fat related to the cold carcass weight (PCF) of male lambs (M) and female lambs $(F)$ in different feeding methods (M1, M2 and M3), and t test (ho:b=1)

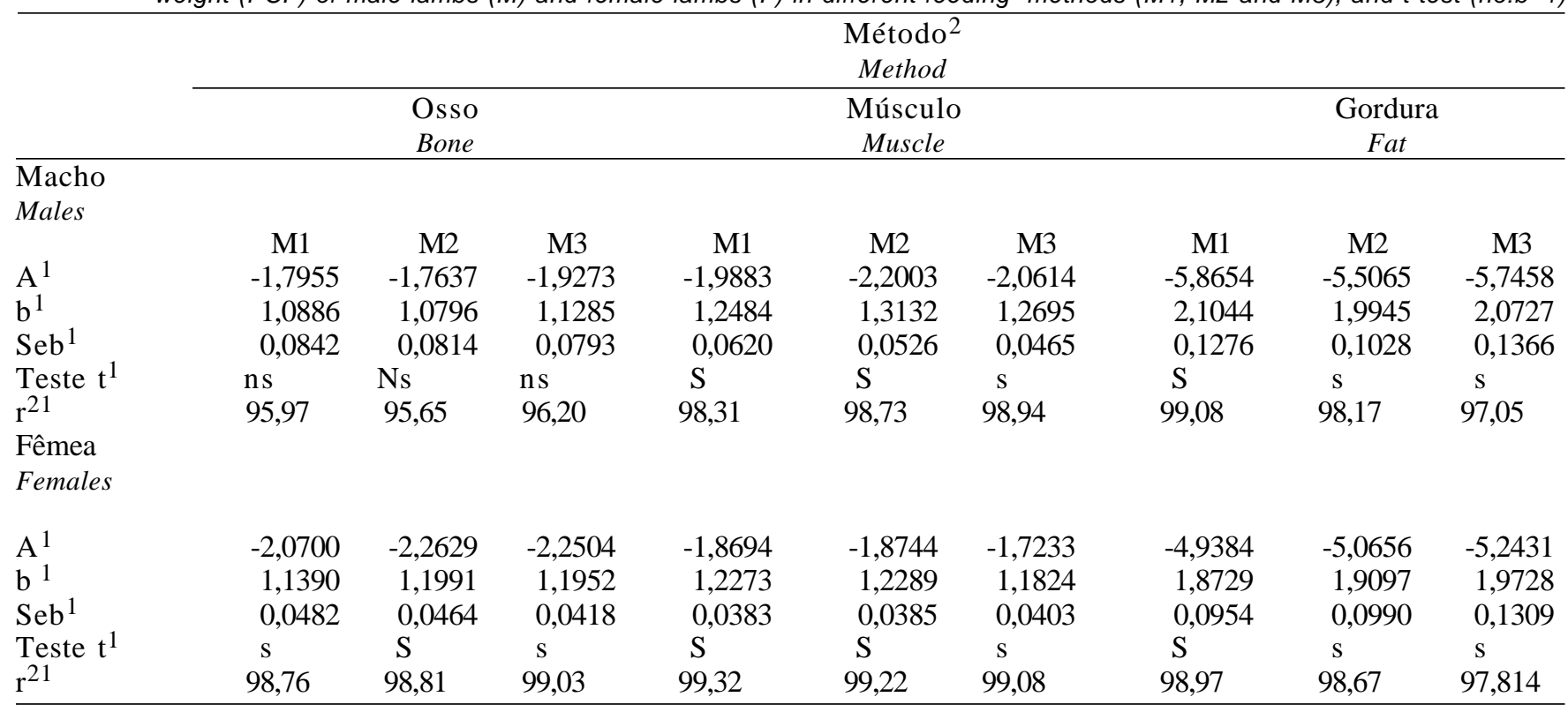

1. $A=$ interceptor; $b=$ coeficiente de alométria; $S e b=$ erro-padrão; Teste $t: s=$ significativo para $(P<0,05)$, ns $=$ não-significativo para $(P>0,05) ; r^{2}=$ Coeficiente de determinação.

2. $M 1$ = método um; $M 2$ = método dois; $M 33$ = método três.

1. $A=$ intercept; $b=$ alometric coefficient; $S e b=$ standard error; $t$ test: $s=$ significant at $P<.05$, ns = not significant at $(P>.05) ; r^{2}=$ coefficient of determination.

2. $M 1=$ method one; $M 2=$ method two; $M 3=$ method three.

R. Bras. Zootec., v.31, n.6, p.2283-2289, 2002 
Tabela 4 - Parâmetros estimados das equações de alometria e erro-padrão para osso, músculo e gordura da perna em relação ao peso de carcaça fria (PCF) de cordeiros machos (M) e fêmeas (F) sob três métodos de alimentação (M1, M2 e M3) e teste $t(H o: b=1)$

Table 4 - Estimated parameters of alometric equations and pattern error for bone, muscle and leg fat related to the cold carcass weight (PCF) of male lambs (M) and female lambs (F) in three feeding methods (M1, M2 and M3), and t test (ho:b=1) weight $(P C F)$ of male lambs $(M)$ and female lambs $(F)$ in different feeding methods (M1, M2 and M3), and t test (ho: $b=1)$

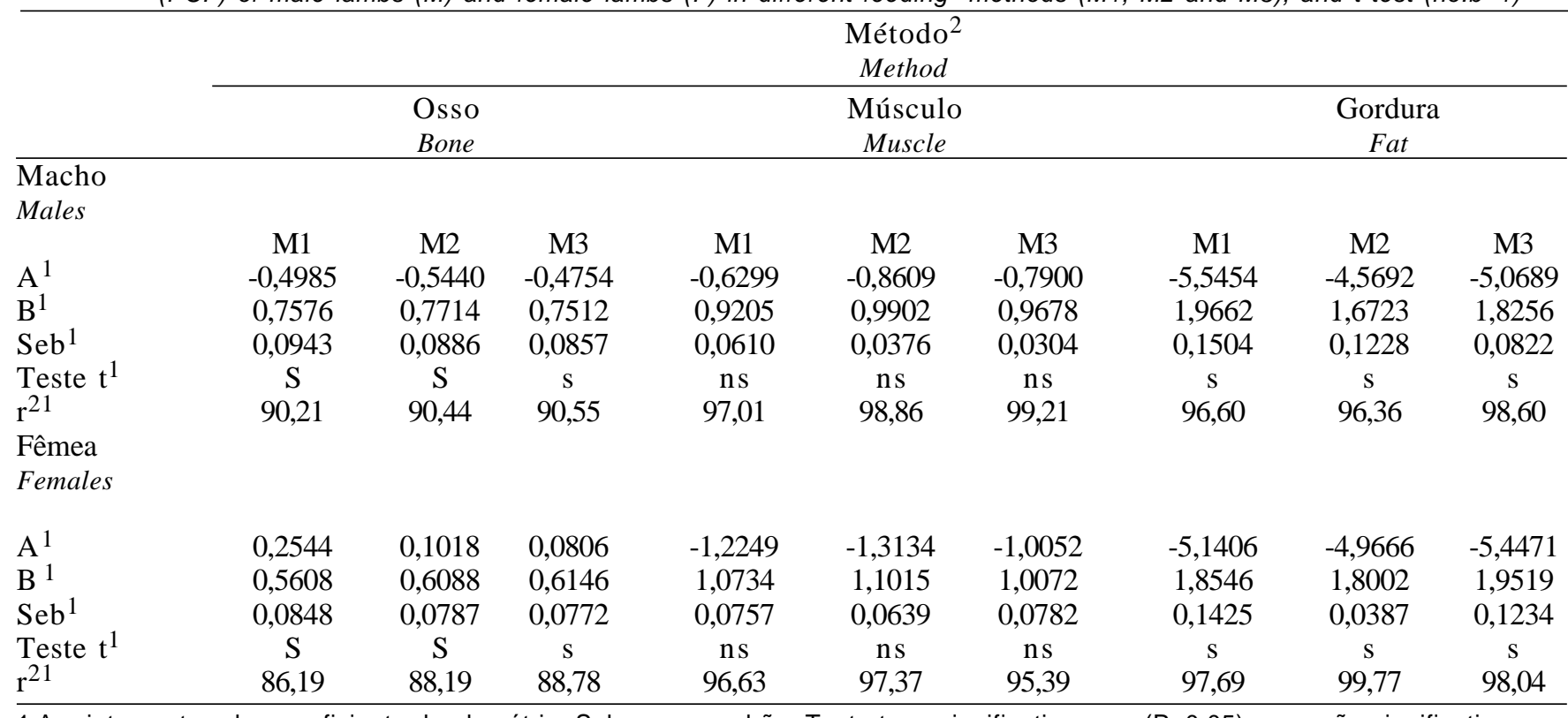

$1 . A=$ interceptor; $b=$ coeficiente de alométria; $S e b=$ erro-padrão; Teste $t: s=$ significativo para $(P<0,05)$, ns $=$ não-significativo para $\left(P^{3} 0,05\right) ; r^{2}=$ Coeficiente de determinação.

2. $M 1$ = método um; $M 2$ = método dois; M3 = método três.

1. $A=$ intercept; $b=$ alometric coefficient; $S e b=$ standard error; $t$ test: $s=$ significant at $P<.05$, ns $=$ not significant at $(P>.05) ; r^{2}=$ coefficient of determination. 2. $M 1=$ method one; $M 2$ = method two; $M 3$ = method three.

1,300 para gordura da costela. Os resultados encontrados pelos autores citados são discordantes aos do presente trabalho, que mostra que o crescimento relativo do osso, músculo e gordura são influenciados pela raça.

De acordo com os coeficientes alométricos na (Tabela 4), verificou-se que, em relação à carcaça fria, osso, músculo e gordura da perna apresentaram diferentes ritmos de crescimento, isto é, crescimento precoce, isométrico e tardio, respectivamente. Os resultados são concordantes aos encontrados por Osório \& Guerreiro (1994), que, ao estudarem o crescimento dos diferentes tecidos da perna de cordeiros Ideal e cruzas Texel x Ideal, observaram coeficientes de alometria para osso de 0,601 e 0,684, para músculo 1,027 e 1,115 e para gordura 2,305 e 2,168 , respectivamente, em relação ao peso da carcaça fria (PCF); no entanto, deve ser salientado que são animais de outro genótipo e alimentados em campo nativo. Huidobro \& Villapadierna (1992) verificaram coeficientes de crescimento de $0,796(b<1)$ para músculo, 0,620 (b=1) para osso e 2,020 (b>1)

R. Bras. Zootec., v.31, n.6, p.2283-2289, 2002 para gordura em relação ao peso da meia carcaça.

\section{Conclusões}

O crescimento muscular da paleta é precoce nos machos e tardio nas fêmeas, ocasionando que, em cordeiros jovens e a um mesmo peso de carcaça, os machos apresentem maior quantidade de músculo, nesse corte, do que as fêmeas.

O crescimento da gordura é tardio para machos e fêmeas, independentemente do método de alimentação a que são submetidos.

O crescimento muscular e adiposo da costela é tardio, significando que maior quantidade de músculo nesse corte será obtida com altos pesos de carcaça, mas em contrapartida, com altos depósitos de gordura.

A gordura da perna, independentemente de sexo e método de alimentação, cresce tardiamente, enquanto o crescimento muscular é isométrico, indicando que a maior relação músculo/gordura, nesse corte, será obtida com carcaças de animais jovens.

\section{Literatura Citada}


BERG, R.T.; BUTTERFIELD, R.M. New concepts of cattle growth. Sydney: Sydney University Press, 1976. 240p.

BERG, R.T.; ANDERSEN, B.B.; LIBORIUSSEN, T. Growth of bovine tissues. 1. Genetic influence on growth fatteems muscle, fat and bovine in young bull. Animal Production, v.26, n.3, p.245-258, 1978.

BUTTERFIELD, R.M.; THOMPSON, J.M. Changes in body composition relative to weight and matury of large and small strais of Australian Merino Rams. 4. Fat depots and bones. Animal Production, v. 37, p. 423-431, 1983.

BUTTERFIELD, R.M.,JOHNSON, E. R. The effect og growth rate of muscle in cattle on conformation as influence by muscle-weigth distribution. In: GROWTH AND DEVELOPMENT OF MAMMALS. Butterworth. London, p.212-223, 1968.

HAFEZ, E.S.E. Introducciòn al crecimiento animal. Dessarrolo y nutricion animal. Zaragosa: Acribia, 1972. p.11-29.

HAFEZ, E.S.E.; DYER, I. A. Necesidades Minerales Desarrollo y Nutricion Animal. Zaragoza: Acribia, 1972. p.381-403.

HAFEZ, E.S.E. Crescimento prenatal. In: HAFEZ, E.S.E.; DYER, I. A. Desarrollo y nutrition animal. Zaragoza: Acribia, 1972. p.33-54.

HUIDOBRO F. R.; CAÑEQUE, V. Producción de carne de corderos de raza Manchega. 5. Crescimiento relativo del quinto cuarto y de los teidos y piezas de la canal. Investigacion Agraria: Producción y Sanidad Animals, v.9, n.2, p.95108, 1994.

HUIDOBRO, F.R.; VILLAPADIERNA, A. Estudios sobre crescimento y desarrolo en corderos de raza Manchega. Madrid, Espanha, Universidad Complutense 1992. 191p. (Tesis Doctoral) - Facultad de Veterinaria, Universidad Complutense, 1992.

HUXLEY, J.S. Problems of relative growth. London: Methuen, 1932. 276p.

JONES, S.D.M. The accumulation and distribution of fat in and ram lambs. Journal of Animal Science, n.6, p.381-386, 1982.

OSÓRIO, J.C.S.; GUERREIRO, J.L.V. Produção de carne na raça Ideal. In: ENCONTRO DE CRIADORES DE RAÇA IDEAL, 1., 1994, Pelotas. Resumo... Universidade Federal de Pelotas, 1994. p.57.

ROQUE, A.P.; OSÓRIO, J.C.S.; JARDIM, P.O. et al. Produção de carne em ovinos de cinco genótipos. 6. Desenvolvimento relativo. Ciência Rural, v.29, n.3, p.549 - 553, 1999.

SAS INSTITUTE. SAS User's guide: statistics. v.2, version 6, 4.ed., Cary: 1996. 300p.

SANTOS, C. L., PEREZ, J. R. O., MUNIZ, J. A. et al. Alometria dos componentes teciduais dos cortes da carcaça de cordeiros da raça Santa Inês. In: REUNIÃO ANUAL DA SOCIEDADE BRASILEIRA DE ZOOTECNIA, 1999, 36., Porto Alegre. Anais... Porto Alegre: Sociedade Brasileira de Zootecnia, 1999. p. 350.

SILVA, L.F.; PIRES, C.C.; ZEPPENFELD, C. et al. Estudo da composição e características da carcaça de cordeiros. In: REUNIÃO ANUAL DA SOCIEDADE BRASILEIRA DE ZOOTECNIA, 35., 1998, Botucatu. Anais... Botucatu: Sociedade Brasileira de Zootecnia, 1998. p.515-517.

WYNN, P.C.; THWAITES, C.J. The relative growth and development of the carcass tissues of merino and crossbred rams and wethers. Australian Journal of Agriculture v.32, p.947-956, 1981. 